\title{
Author's response
}

We reported that high levels of red cell distribution width (RDW) were associated with ST elevation myocardial infarction (STEMI) in young patients in Cardiology Journal [1]. We read with interest the letter to editor about our article titled "Red cell distribution width: A novel inflammatory marker in clinical practice" by Demirkol et al. [2]. We thank for comments and we would like to reply this important comments on our article.

We agree with Demirkol et al. [2] about association between RDW and other inflammatory markers. As they pointed out inflammation may cause changes in red blood cell maturation by disturbing the red cell membrane, leading to increased RDW [3]. Furthermore, elevated levels of inflammatory molecules are markers of atherosclerotic disease activity and also indicate an increased risk for the progression of atherosclerosis $[4,5]$.

As the authors rightly denoted, inflammatory markers can give information to clinicians about the atherosclesosis and the endothelial inflammatory condition of the patients. But unfortunately we did not evaluate other inflammatory markers and did not describe it in limitation section. Moreover, the investigators showed a relationship between generalized inflammation and elevated levels of RDW and demonstrated an association of RDW with high sensitive $\mathrm{C}$-reactive protein and erythrocyte sedimentation rate which are indicators of inflammation [6]. So RDW can be accepted as an inflammatory marker in our study.

Cardiovascular risk factors such as hypertension, diabetes mellitus, smoking and hyperlipidemia may affect both of the inflammotory markers and RDW. In our study group, number of patients with diabetes mellitus, hypertension and smoking were similar between young patients with or wit- hout STEMI. In young patients with STEMI, male gender, history of hyperlipidemia and family history of coronary artery disease were more frequently than patients without STEMI. Although history of hyperlipidemia was more frequently in patients with STEMI, serum levels of LDL-cholesterol, total cholesterol and tryglicerides were similar in both groups. According to similarities between the two groups on the basis of these cardiovascular risk factors, the effects of these risk factors on levels of RDW were negligible in our study group.

Finally, all measurements were performed 30 min after blood collection in our study. This delay depended on our hospital procedures. This situation was not done delibrately. We think that this delay is acceptable for our study.

\section{References}

1. Uysal OK, Duran M, Ozkan B et al. Red cell distribution width is associated with acute myocardial infarction in young patients. Cardiol J, 2012; 19: 597-602.

2. Demirkol S, Balta S, Cakar M, Unlu M, Arslan Z, Kucuk U. Red cell distribution width: A novel inflammatory marker in clinical practice. Cardiol J, 2013; 20: 209.

3. Förhécz Z, Gombos T, Borgulya G et al. Red cell distribution width in heart failure: prediction of clinical events and relationship with markers of ineffective erythropoiesis, inflammation, renal function, and nutritional state. Am Heart J, 2009; 158: 659-666.

4. Libby P. What have we learned about the biology of atherosclerosis? The role of inflammation. Am J Cardiol, 2001; 88: 3J-6J.

5. Karabulut A, Uyarel H, Uzunlar B et al. Elevated red cell distribution width level predicts worse postinterventional thrombolysis in myocardial infarction flow reflecting abnormal reperfusion in acute myocardial infarction treated with a primary coronary intervention. Coron Artery Dis, 2012; 23: 68-72.

6. Lippi G, Targher G, Montagnana M et al. Relation between red blood cell distribution width and inflammatory biomarkers in a large cohort of unselected outpatients. Arch Pathol Lab Med, 2009; 133: 628-632.

Onur Kadir Uysal', Mustafa Duran ${ }^{1}$, Bugra Ozkan', Durmus Yildiray Sahin ${ }^{3}$,Kamuran Tekin ${ }^{3}$, Zafer Elbasan ${ }^{3}$, Murat Cayli ${ }^{3}$

${ }^{1}$ Kayseri Education and Research Hospital, Department of Cardiology, Kayseri, Turkey Hastaneler Caddesi, No: 78, Kocasinan, Kayseri, Turkey, e-mail: onurkadir@gmail.com

${ }^{2}$ Burdur Bucak State Hospital, Department of Cardiology, Burdur, Turkey ${ }^{3}$ Adana Numune Education and Research Hospital, Department of Cardiology, Adana, Turkey 